\title{
Self-assembly of tetraphenylethylene-based dendron into blue fluorescent nanoparticles with aggregation induced enhanced emission $^{\S}$
}

\author{
NITHIYANANDAN KRISHNAN, M A HANNA AMEENA, SIRIKI ATCHIMNAIDU, \\ DEVANATHAN PERUMAL, MURALI GOLLA, JITHU KRISHNA and REJI VARGHESE*
}

School of Chemistry, Indian Institute of Science Education and Research (IISER) Thiruvananthapuram, Thiruvananthapuram, Kerala 695 551, India

E-mail: reji@iisertvm.ac.in

MS received 25 July 2018; revised 30 August 2018; accepted 5 September 2018; published online 26 September 2018

\begin{abstract}
Luminescent organic nanoassemblies have received great attention in recent years due to their potential applications in material science and bioimaging. Since most of the fluorophores undergo aggregationcaused quenching in the solid state, their technological applications are limited. Hence, there is a high demand for the design of fluorophores which show enhanced emission in the aggregated and solid states. Herein we report the design and synthesis of a tetraphenylethylene based dendron through multistep organic reactions. Very weak emission is observed for the dendron in the molecularly dissolved state, which is attributed to the rotational relaxation of intramolecular $\mathrm{C}\left(\mathrm{sp}^{2}\right)-\mathrm{C}\left(\mathrm{sp}^{2}\right)$ bond rotation in the excited state. The aggregates of the dendron are prepared with the addition of a 'poor' solvent into a solution of the dendron in a 'good' solvent. A huge enhancement in fluorescence is observed in the aggregated state, which is attributed to the restriction of intramolecular $\mathrm{C}\left(\mathrm{sp}^{2}\right)-\mathrm{C}\left(\mathrm{sp}^{2}\right)$ bond rotation and makes the radiative decay as the main decay channel for the aggregated state. The induced self-assembly of the dendron with the addition of 'poor' solvent results in the formation of emissive nanoparticles. We hope the blue emissive nanoparticles may find applications in material science and bioimaging.
\end{abstract}

Keywords. Self-assembly; fluorescence; nanoparticles.

\section{Introduction}

Design and synthesis of luminescent organic nanoassemblies are extremely important due to their potential applications in material science and recent years have witnessed the emergence of different types of fluorescence nanostructures. ${ }^{1}$ However, in most of the cases, self-assembly of the fluorophores leads to the quenching of fluorescence, which is commonly known as aggregation-caused quenching (ACQ) of fluorescence. Because for most practical applications, the fluorescent materials have to be applied in the solid state where the fluorophore typically tends to form aggregates and become non-fluorescent, which limits their applications in material science. Various strategies have been demonstrated in recent years by different research

\footnotetext{
*For correspondence

$\S$ Dedicated to Professor M V George on the occasion of his $90^{\text {th }}$ Birth Anniversary.
}

groups for the prevention of aggregation of fluorescent molecules in the aggregated and solid states. The decoration of the fluorophore core with bulky side chains or dendritic wedges have shown to be a promising strategy. ${ }^{2}$ Other approach involves the insulation of the fluorophore with protective sheaths such as cyclodextrins, which significantly block the $\pi-\pi$ interaction of the fluorophore in the solid state. ${ }^{3}$ Though there have been a few approaches demonstrated in the literature regarding the prevention of aggregation of the fluorophore in the solid state, their potentiality in practical applications has been limited. This is mainly because with the incorporation of bulky side chains or encapsulation within a molecular sheath affect the optical properties of the fluorophore in an undesired way. Hence, it is extremely important to design a strategy, which either allows the prevention of aggregation of the fluorophore in the solid-state without affecting the optical properties or enhances the fluorescence upon aggregation. 
Tang and co-workers have recently developed a series of fluorophores, which are nearly non-fluorescent in the molecularly dissolved state (i.e., monomeric state), but enhances the fluorescence several hundred-fold upon aggregation. ${ }^{4}$ This phenomenon is termed as aggregation induced enhanced emission (AIEE). ${ }^{5}$ The key structural feature required for a molecular system to show AIEE is the presence of several aromatic rings typically connected to a central core through single bonds, which have very low rotational energy barrier. Due to the low rotational energy barrier of $\mathrm{C}-\mathrm{C}$ bonds connecting the aromatic rings, the excited state of the monomer undergoes extremely fast rotational relaxation through intramolecular $\mathrm{C}-\mathrm{C}$ bond rotation. This makes non-radiative relaxation as the major decay pathway and hence the molecule is very weakly emissive in the monomeric state. Whereas the intramolecular $\mathrm{C}-\mathrm{C}$ bond rotation is completely arrested in the aggregated state, which makes radiative recombination as the major relaxation pathway for the excited state and hence the molecule is highly emissive in the aggregated state. This unique behavior of this class of molecules has attracted researchers for the application of this class of molecules in different fields including a light emitting diode, ${ }^{6}$ diagnosis, ${ }^{7}$ bioimaging, ${ }^{8}$ etc. Among the different classes of molecules that exhibit the phenomenon of AIEE, tetraphenylethylene is the most investigated. ${ }^{9}$ In view of the potential applications of this class of molecules in material science and imaging applications, design and synthesis of new derivatives of tetraphenylethylene that exhibit AIEE are extremely important.

Herein we report the design and synthesis of a novel class of tetraphenylethylene based dendron (1). The design strategy involves the incorporation of two tetraphenylethylene unit to a central resorcinol core through triazole linkages. Monomeric state of the molecule is weakly emissive due to the intramolecular $\mathrm{C}\left(\mathrm{sp}^{2}\right)-\mathrm{C}\left(\mathrm{sp}^{2}\right)$ bond rotation. The self-assembly of the dendron is achieved with the addition of a poor solvent (water) into a solution of the dendron in a good solvent (DMSO). A significant enhancement in fluorescence is observed in the aggregated state of the dendron due to the restriction of intramolecular $\mathrm{C}\left(\mathrm{sp}^{2}\right)-$ $\mathrm{C}\left(\mathrm{sp}^{2}\right)$ bond rotation, as is evident from the steady state and time-resolved fluorescence experiments. The dendron self-assembles into spherical nanoparticle with the addition of water into the DMSO solution of the dendron as evident from various microscopic techniques including scanning electron microscope (SEM) and transmission electron microscope (TEM) analyses. The emissive (blue) nanoparticles are also characterized using fluorescence microscopic analysis.

\section{Experimental}

\subsection{Materials and methods}

All the chemicals used for the organic syntheses were purchased from Sigma Aldrich and were used as received. TLC analyses were performed on aluminium plates coated with silica gel 60 F254, and column chromatography was performed on 200-400 mesh silica gel. Melting points were measured on Stuart SMP50 automated melting point apparatus and are uncorrected. ${ }^{1} \mathrm{H}$ and ${ }^{13} \mathrm{C}$ NMR spectra were recorded on a Bruker Avance $500 \mathrm{MHz}$ DPX spectrometer using 1,1,1,1-tetramethylsilane (TMS) as the internal standard. Water used for all studies was Milli Q deionised water $(18.2 \mathrm{M} \Omega \mathrm{cm})$. Mass measurements were performed on a Shimadzu GCMSQP-2010 in EI mode. ESI-MS analyses were carried out on Thermo Scientific Q-Exactive plus orbitrap mass spectrometer in positive mode. The confocal microscopic analysis was carried out on Leica TCS SP5 X. Samples were prepared by depositing $5 \mu \mathrm{L}$ aggregates on a clean glass slide. After air-drying the samples, an aliquot of antifade mountant, ProLong Gold was dropped over the sample and was carefully covered with a coverslip avoiding the air bubbles and was kept undisturbed for $30 \mathrm{~min}$. The slides were then imaged at $60 \mathrm{X}$ magnification in the presence of immersion oil. TEM analyses were carried out on FEI Tecnai F20 (120 kV) high-resolution TEM. Samples were prepared by depositing $2 \mu \mathrm{L}$ of the sample on a 400 mesh carbon coated copper grid (Ted Pella, Inc.). Samples were allowed to adsorb on the grid for $2 \mathrm{~min}$ and then the excess sample was wicked with a piece of filter paper. FESEM were carried out on FEI Nova NanoSEM 450 (FEG type). The sample for FE-SEM was prepared by drop casting $2 \mu \mathrm{L}$ of the sample onto a freshly cleaved mica surface. Absorption spectra were recorded using a quartz cuvette of 10 $\mathrm{mm}$ path length on a Shimadzu UV-3600 Vis-NIR spectrophotometer having a Peltier controlled cell holder. Steady-state fluorescence spectra were recorded on a Horiba Jobin Yvon Fluorimeter equipped with a thermostat Peltier cell holder, in a quartz cuvette of $10 \mathrm{~mm}$ path length. Temperature dependent emission spectra were recorded from $20-90^{\circ} \mathrm{C}$ at an interval of $5^{\circ} \mathrm{C}$ and the sample was equilibrated for $5 \mathrm{~min}$ at each temperature before measurement. Fluorescence lifetime of the samples were determined using Horiba Jobin Yvon time-correlated single photon counter.

\subsection{Synthesis}

2.2a Synthesis of $1 c$ : In a $250 \mathrm{~mL}$ two-necked round bottom flask, $10.0 \mathrm{~g}(60.0 \mathrm{mmol})$ of diphenylmethane (1) was dissolved in $150 \mathrm{~mL}$ of distilled THF under a $\mathrm{N}_{2}$ atmosphere. After cooling the mixture to $0^{\circ} \mathrm{C}, 50 \mathrm{~mL}$ of n-butyllithium (1.6 M in hexane, $75 \mathrm{mmol}$ ) was slowly added through a syringe and stirred at $0^{\circ} \mathrm{C}$ for $1 \mathrm{~h}$. To the above reaction mixture, $10.2 \mathrm{~g} \quad(50.0 \mathrm{mmol})$ of 4-methylbenzophenone (1a) was added, warmed to room temperature and stirred for $8 \mathrm{~h}$. The reaction mixture was 
quenched with a saturated $\mathrm{NH}_{4} \mathrm{Cl}$ solution and then extracted with DCM. The organic layer was collected and concentrated. Subsequently, the crude product and $0.40 \mathrm{~g}$ of $\mathrm{p}$ toluenesulfonic acid were dissolved into $100 \mathrm{~mL}$ of toluene and the mixture was heated to reflux for $4 \mathrm{~h}$. After cooling down to room temperature, the reaction mixture was extracted with DCM. The organic layer was collected, concentrated and the crude product was purified through silica-gel chromatography using petroleum ether as the eluent to give 1c as white solid (6.6 g, 78\% yield). M.p. = $155^{\circ} \mathrm{C} .{ }^{1} \mathrm{H} \mathrm{NMR}\left(500 \mathrm{MHz}, \mathrm{CDCl}_{3}\right), \delta(\mathrm{ppm})=7.146-$ $7.106(\mathrm{~m}, 9 \mathrm{H}), 7.086-7.042(\mathrm{~s}, 6 \mathrm{H}), 2.290(\mathrm{~s}, 3 \mathrm{H}) ;{ }^{13} \mathrm{C} \mathrm{NMR}$ $\left(125 \mathrm{MHz}, \mathrm{CDCl}_{3}\right), \delta(\mathrm{ppm})=143.96,136.06,131.36$, $131.33,131.22,128.38,127.66,127.60,126.33,126.29$, 21.19. ES-MS m/z for $\mathrm{C}_{27} \mathrm{H}_{23}: 347.1722$ (calcd.); 347.1788 $[\mathrm{M}+\mathrm{H}]^{+}$(expt.).

2.2b Synthesis of $1 \mathrm{~d}$ : In a $250 \mathrm{~mL}$ round bottom flask, 1c $(5.20 \mathrm{~g}, 15.0 \mathrm{mmol})$, N-bromosuccinimide (2.94 g, 16.0 $\mathrm{mmol})$ and benzoyl peroxide $(0.036 \mathrm{~g})$ were dissolved in $80 \mathrm{~mL}$ of $\mathrm{CCl}_{4}$ and was refluxed for $12 \mathrm{~h}$. After completion of the reaction, the mixture was extracted with DCM and washed with water. The organic layer was collected, dried over anhydrous $\mathrm{Na}_{2} \mathrm{SO}_{4}$ and then the solvent was removed under reduced pressure. The crude product was purified by silica-gel chromatography using petroleum ether as eluent to give $\mathbf{1 d}$ as white solid (3.83 g, 60\% yield). M.p. $=136{ }^{\circ} \mathrm{C} .{ }^{1} \mathrm{H}$ NMR $\left(500 \mathrm{MHz}, \mathrm{CDCl}_{3}\right), \delta(\mathrm{ppm})=7.07-7.048(\mathrm{~m}, 11 \mathrm{H}), 6.988-$ $6.944(\mathrm{~m}, 8 \mathrm{H}) ; \quad{ }^{13} \mathrm{C} \mathrm{NMR}\left(125 \mathrm{MHz}, \mathrm{CDCl}_{3}\right), \quad \delta(\mathrm{ppm})$ $=144.00,143.57,143.51,143.45,141.59,140.27,135.74$, 131.69, 131.35, 131.31, 128.44, 127.76, 127.68, 126.62, 126. 55, 33.61. ESI-MS m/z for $\mathrm{C}_{27} \mathrm{H}_{21} \mathrm{Br}: 424.0827,426.0806$ (calcd.); 424.0812, 426.0847[M] ${ }^{+}$(expt.).

2.2c Synthesis of $1 \boldsymbol{e}$ : In a $100 \mathrm{~mL}$ two-neck RB flask, $1.70 \mathrm{~g}(4.0 \mathrm{mmol})$ of $\mathbf{1 d}$ and $0.39 \mathrm{~g}(6.0 \mathrm{mmol})$ of $\mathrm{NaN}_{3}$ were dissolved in anhydrous DMSO under $\mathrm{N}_{2}$ atmosphere. The mixture was allowed to stir at room temperature for $4 \mathrm{~h}$. The reaction mixture was then extracted with DCM, dried over anhydrous $\mathrm{Na}_{2} \mathrm{SO}_{4}$ and concentrated to give the crude product, which was purified through silica column chromatography using $2 \%$ ethyl acetate in petroleum ether as an eluent to afford the product 1e as colorless solid $(97 \%$ yield $)$. M.p. $=136{ }^{\circ} \mathrm{C} .{ }^{1} \mathrm{H} \mathrm{NMR}$ $\left(500 \mathrm{MHz}, \mathrm{CDCl}_{3}\right), \delta(\mathrm{ppm})=7.187-7.022(\mathrm{~m}, 9 \mathrm{H}), 6.972-$ $6.943(\mathrm{~m}, 9 \mathrm{H}), 4.176$ (s, 2H); ${ }^{13} \mathrm{C} \mathrm{NMR}\left(125 \mathrm{MHz}, \mathrm{CDCl}_{3}\right)$, $\delta(\mathrm{ppm})=143.92,143.56,143.51,143.48,141.49,140.28$, 133.28, 131.76, 131.32, 127.75, 127.68, 127.64, 126.57, 126. 55, 54.57. ESI-MS m/z for $\mathrm{C}_{27} \mathrm{H}_{21} \mathrm{~N}_{3}$ : 387.1735 (calcd.); 362.1611[M-28] $]^{+}$(expt.).

2.2d Synthesis of 1g: To a $500 \mathrm{~mL}$ RB flask containing $\mathrm{K}_{2} \mathrm{CO}_{3}(82.194 \mathrm{~g}, 594.707 \mathrm{mmol})$, methyl-3,5dihydroxybenzoate (1f, $10 \mathrm{~g}, 59.47 \mathrm{mmol}$ ) dissolved in THF $(250 \mathrm{~mL})$ was added under nitrogen atmosphere. Subsequently, 18-crown-6 ether was added and the resulting mixture was stirred for $1 \mathrm{~h}$ at room temperature. Propargyl bromide $(53.06 \mathrm{~mL}, 356.82 \mathrm{mmol})$ was added and the reaction mixture was heated to reflux for $16 \mathrm{~h}$. The crude was extracted with DCM, the separated organic layer was dried over anhydrous $\mathrm{Na}_{2} \mathrm{SO}_{4}$ and concentrated under reduced pressure. The crude product purified through silica column chromatography using $9 \%$ ethyl acetate in petroleum ether as eluent to afford the desired product $\mathbf{1 g}$ as a colorless solid (99\%). M.p. $=111^{\circ} \mathrm{C} .{ }^{1} \mathrm{H} \mathrm{NMR}\left(500 \mathrm{MHz}, \mathrm{CDCl}_{3}\right), \delta(\mathrm{ppm})=$ $7.330-7.325(\mathrm{~d}, J=2.3 \mathrm{~Hz}, 2 \mathrm{H}), 6.84(\mathrm{t}, J=2.3 \mathrm{~Hz}, 1 \mathrm{H})$, $4.746(\mathrm{~d}, J=2.40 \mathrm{~Hz}, 4 \mathrm{H}), 3.941(\mathrm{~s}, 3 \mathrm{H}), 2.572(\mathrm{t}, J=$ $2.40 \mathrm{~Hz}, 2 \mathrm{H}) ;{ }^{13} \mathrm{C} \mathrm{NMR}\left(125 \mathrm{MHz}, \mathrm{CDCl}_{3}\right), \delta(\mathrm{ppm})=$ 165.43, 157.50, 131.14, 107.89, 106.51, 74.96, 55.11,51.33. GC-MS (EI)-m/z for $\mathrm{C}_{14} \mathrm{H}_{12} \mathrm{O}_{4}: 244.07$ (calcd.); 244 (expt.).

2.2e Synthesis of $\boldsymbol{1 h}$ : To a stirred suspension of $\mathrm{LiAlH}_{4}$ (2.527 g, $66.5329 \mathrm{mmol})$ in dry THF (150 mL), $1 \mathrm{~g}(3.25$ $\mathrm{g}, 13.3066 \mathrm{mmol}$ ) was added at $0{ }^{\circ} \mathrm{C}$, and allowed to stir for $2 \mathrm{~h}$ at room temperature. The reaction mixture was carefully quenched in ice-bath by the dropwise addition of ice-cold water. The organic layer was extracted using DCM, dried over anhydrous $\mathrm{Na}_{2} \mathrm{SO}_{4}$ and concentrated under reduced pressure. Subsequently, the crude product was purified through silica gel column chromatography using $13 \%$ ethyl acetate in petroleum ether as an eluent to afford the desired product $\mathbf{1 h}$ as a colorless solid (74\%). M.p. $=73{ }^{\circ} \mathrm{C} .{ }^{1} \mathrm{H} \mathrm{NMR}\left(500 \mathrm{MHz}, \mathrm{CDCl}_{3}\right), \delta(\mathrm{ppm})=$ $6.579(\mathrm{~s}, 2 \mathrm{H}), 6.481(\mathrm{~s}, 1 \mathrm{H}), 5.215(\mathrm{t}, J=5.5 \mathrm{~Hz}, 1 \mathrm{H})$, $4.760(\mathrm{~s}, 4 \mathrm{H}), 4.440(\mathrm{~d}, J=5.5 \mathrm{~Hz}, 2 \mathrm{H}), 3.331(\mathrm{~s}, 2 \mathrm{H}){ }^{13}$ $\mathrm{C}\left(125 \mathrm{MHz}, \mathrm{CDCl}_{3}\right), \delta(\mathrm{ppm})=158.87,143.58,106.24$, 101.53, 78.37, 75.69, 65.14, 55.93. ESI-MS $\mathrm{m} / \mathrm{z}$ for $\mathrm{C}_{13} \mathrm{H}_{13} \mathrm{O}_{3}: 217.0789$ (calcd.); 217.0855[M $\left.+\mathrm{H}\right]^{+}$(expt.).

2.2f Synthesis of 1: In a $100 \mathrm{~mL}$ two-neck RB flask, $1.16 \mathrm{~g}$ of $1 \mathrm{e}(5.39 \mathrm{mmol})$ and $4.8 \mathrm{~g}$ of $\mathbf{1 h}(12.33 \mathrm{mmol})$ were dissolved in $50 \mathrm{~mL}$ of anhydrous THF, was degassed for 20 min by nitrogen gas purging. To this mixture, $0.301 \mathrm{~g}(0.808$ $\mathrm{mmol})$ of $\left[\mathrm{Cu}\left(\mathrm{CH}_{3} \mathrm{CN}\right)_{4} \mathrm{PF}_{6}\right]$ was added and heated at $55^{\circ} \mathrm{C}$ for $24 \mathrm{~h}$. Reaction completion was confirmed by TLC, then quenched with a saturated $\mathrm{NH}_{4} \mathrm{Cl}$ solution and extracted with DCM. The separated organic layer was dried over anhydrous $\mathrm{Na}_{2} \mathrm{SO}_{4}$ and concentrated under reduced pressure to get the crude product as a solid. The crude was purified through silica column chromatography by using $2 \%$ DCM in methanol as an eluent to afford the expected product $\mathbf{1}$ as colorless solid (80\%). M.p. $=337^{\circ} \mathrm{C} .{ }^{1} \mathrm{H}$ NMR $(500 \mathrm{MHz}$, DMSO$\left.\mathrm{d}_{6}\right), \delta(\mathrm{ppm})=8.200(\mathrm{~s}, 2 \mathrm{H}), 7.127-7.055(\mathrm{~m}, 22 \mathrm{H}), 6.972$ $6.939(\mathrm{~m}, 16 \mathrm{H}), 6.571(\mathrm{~s}, 3 \mathrm{H}), 5.512(\mathrm{~s}, 4 \mathrm{H}), 5.164(\mathrm{t}, J=$ $5.7 \mathrm{~Hz}, 1 \mathrm{H}), \quad 5.079(\mathrm{~s}, 4 \mathrm{H}), 4.415(\mathrm{~d}, J=5.7 \mathrm{~Hz}, 2 \mathrm{H})$; ${ }^{13} \mathrm{C}$ NMR $\left(125 \mathrm{MHz}, \mathrm{CDCl}_{3}\right), \delta(\mathrm{ppm})=159.59,144.49$, $144.23,143.82,143.41,143.35,143.24,141.79,140.00$, $132.26,132.01,131.28,131.26,131.24,127.79,127.77$, $127.69,127.50,126.68,126.64,126.62,122.72,105.93$, 101.13, 65.04, 62.13, 53.99. ESI-MS m/z for $\mathrm{C}_{67} \mathrm{H}_{55} \mathrm{~N}_{6} \mathrm{O}_{3}$ : 991.4257 (calcd.); $991.4313[\mathrm{M}+\mathrm{H}]^{+}$(expt.). 


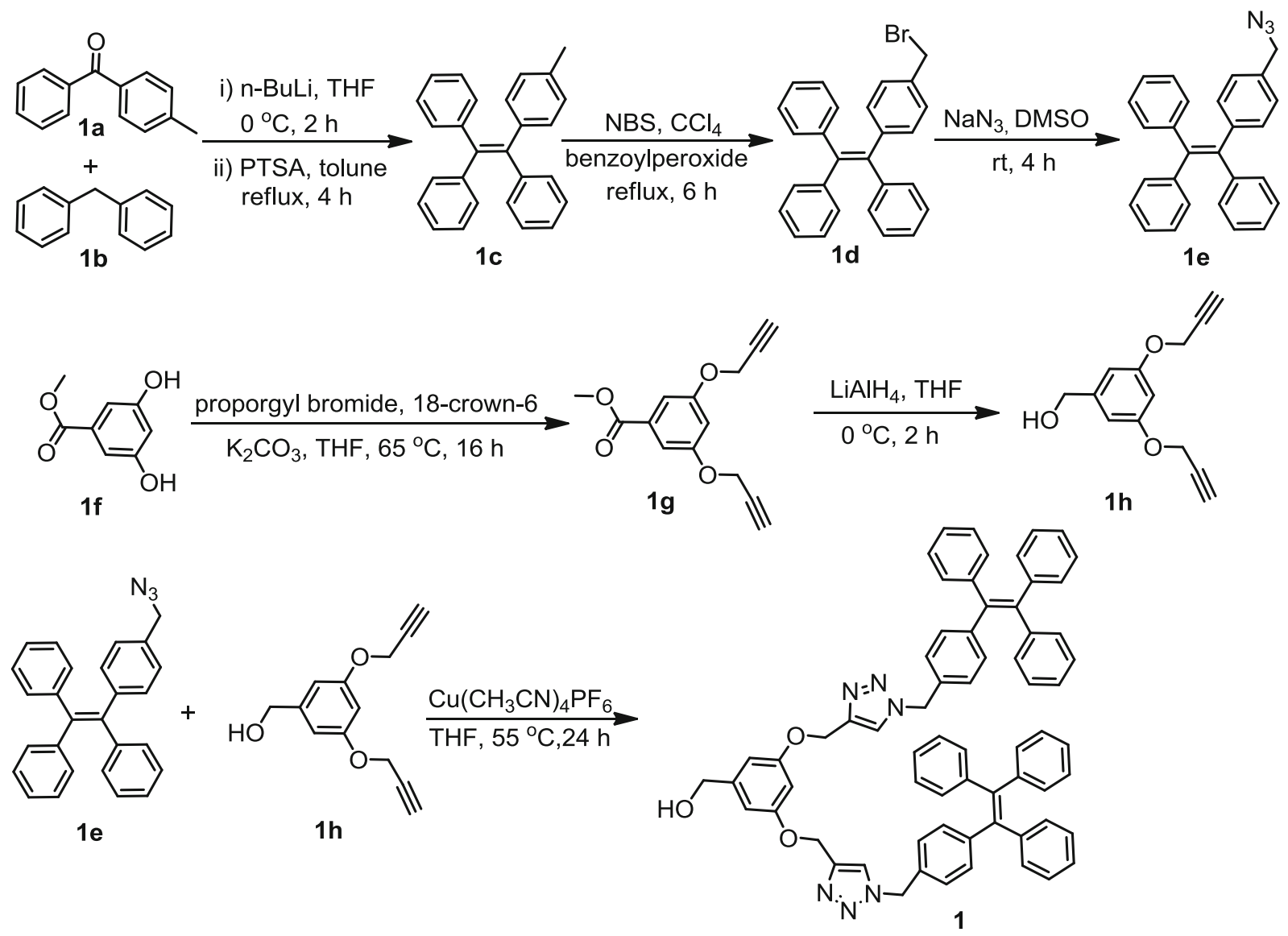

Scheme 1. Scheme for the synthesis of tetraphenylethylene based dendron $\mathbf{1}$.

\section{Results and Discussion}

\subsection{Synthesis of the dendron}

The strategy used for the synthesis of $\mathbf{1}$ is shown in Scheme 1. For the synthesis of $\mathbf{1}$, we adopted $\mathrm{Cu}(\mathrm{I})$-catalysed alkyne-azide cycloaddition (CuAAC) reaction, also known as "click" reaction as the key step. For this purpose, initially, azide functionalized tetraphenylethylene (1c) was synthesized from commercially available 4-methylbenzophenone and diphenyl methane through multi-step organic reactions. Condensation of 4-methylbenzophenone and diphenylmethane in the presence of n-butyllithium and p-toluenesulfonic acid gave methylated tetraphenylethylene (1c). Methylated tetraphenylethylene was then converted to the corresponding bromomethyl derivative (1d) by the treatment with N-bromosuccinimide (NBS), which was then converted into the corresponding azide derivative (1e) by the reaction with sodium azide. Bis-alkyne functionalized benzyl alcohol (1h) was synthesized from commercially available methyl 3,5-dihydroxybenzoate using two-step organic reactions. The reaction of methyl 3,5-dihydroxybenzoate with propargyl bromide in the presence of $\mathrm{K}_{2} \mathrm{CO}_{3}$ and 18-crown-6 provided the corresponding bis-alkyne derivative (1g). Subsequently, lithium aluminium hydride reduction of $\mathbf{1 g}$ furnished methyl-3,5-bis(prop-2-yn-1-yloxy)methanol (1h). Finally, CuAAC reaction between azide functionalized tetraphenylethylene (1e) and bis-alkyne functionalized benzyl alcohol (1h) furnished $\mathbf{1}$ in good yield. All the compounds were purified by using column chromatography and characterized by ${ }^{1} \mathrm{H},{ }^{13} \mathrm{C}$ spectroscopic and mass spectrometric analyses. Details of synthesis and characterization are provided in the experimental section.

\subsection{Photophysical studies}

Initially, the photophysical behavior of $\mathbf{1}$ was investigated in DMSO in which the dendron exists as monomeric species. UV-Vis absorption spectrum of $\mathbf{1}$ in DMSO $(20 \mu \mathrm{M})$ shows the characteristic absorption of monomeric tetraphenylethylene with a maximum centered at $310 \mathrm{~nm}$ (Figure 1a). Similarly, the emission spectrum shows the characteristic emission of tetraphenylethylene centered at $356 \mathrm{~nm}\left(\lambda_{\mathrm{ex}}=310 \mathrm{~nm}\right)$ 
(a)

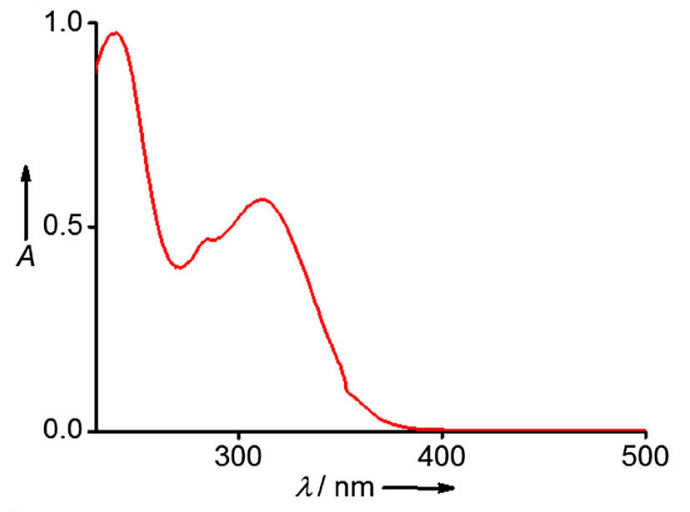

(c)

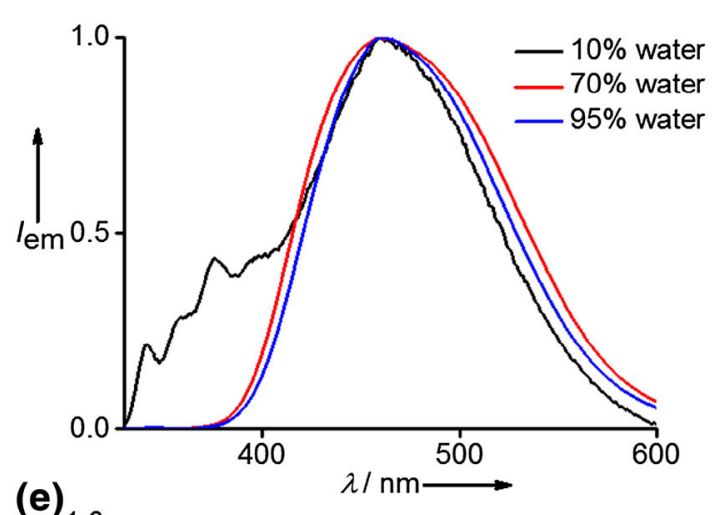

(e)

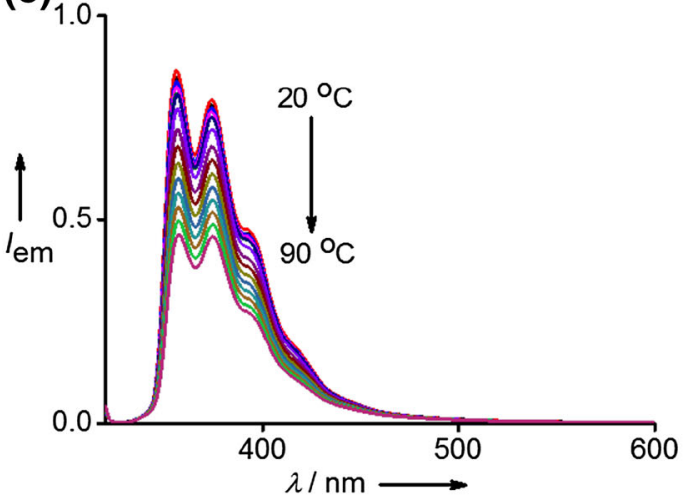

(b)

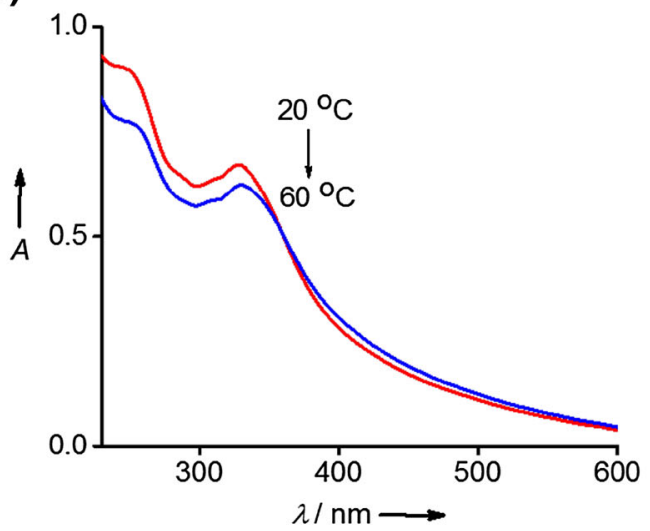

(d)

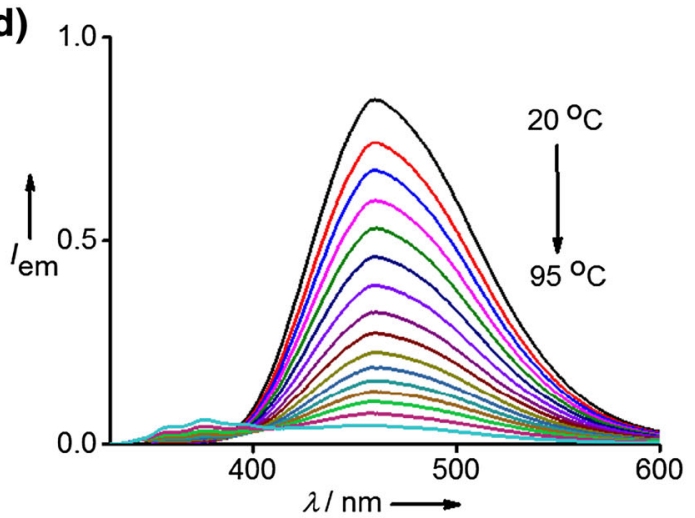

(f)

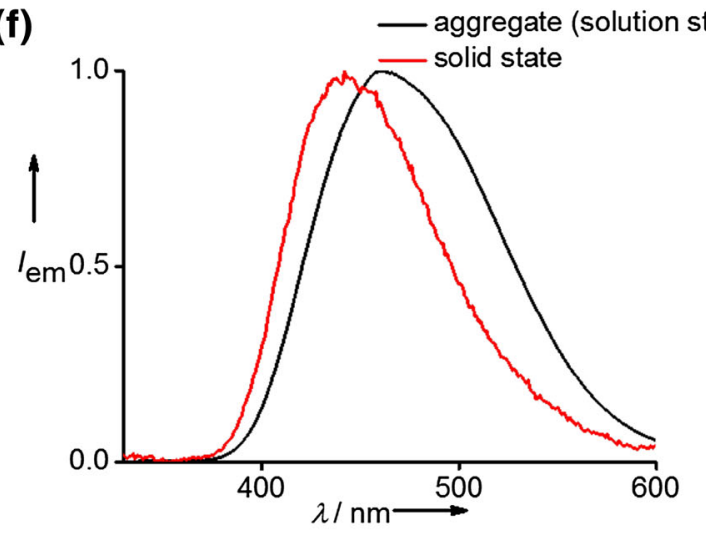

Figure 1. (a) Absorption spectrum of $\mathbf{1}$ in DMSO; (b) Temperature-dependent absorption spectra of $\mathbf{1}$ in 95:5 of water:DMSO mixture; (c) Emission spectra of 1 with different water fractions. Temperature dependent emission spectra of 1; (d) 95:5 of water:DMSO ( $\lambda_{\text {exc }}=325 \mathrm{~nm}$ ); (e) DMSO $\left(\lambda_{\text {exc }}=310 \mathrm{~nm}\right)$; (f) Comparison of emission spectra of $\mathbf{1}$ in solid state $\left(\lambda_{\mathrm{exc}}=320 \mathrm{~nm}\right)$ and aggregated state (in solution).

with a quantum yield of $7 \%$. The self-assembly of $\mathbf{1}$ was achieved by the addition of water into the DMSO solution of $\mathbf{1}$. Though 1 started to aggregate even at $10 \%$ water, we have taken a composition of 95:5 of water:DMSO in all our studies $([\mathbf{1}]=20 \mu \mathrm{M})$. A redshift of $10 \mathrm{~nm}$ with a broadening of the band is observed with the addition of $95 \%$ water into the DMSO solution of $\mathbf{1}$ at $20^{\circ} \mathrm{C}$, clearly indicating the aggregation of 1 with the addition of water (Figure 1b). The absorption maximum of $\mathbf{1}$ in water:DMSO (95:5) is $320 \mathrm{~nm}$.
Very interestingly, the emission spectrum of $\mathbf{1}$ in water:DMSO at $20^{\circ} \mathrm{C}$ shows a drastic red-shift to 460 $\mathrm{nm}$ (104 nm red shift compared to the monomeric species) along with a huge enhancement in the fluorescent intensity when compared with the emission of monomeric species of $\mathbf{1}$. The quantum yield of emission for the aggregated species is $30 \%$. Furthermore, a gradual decrease in the emission maximum at $460 \mathrm{~nm}$ with concomitant blue-shift to $359 \mathrm{~nm}$ is observed with the increase in temperature from 20 to 
(a)

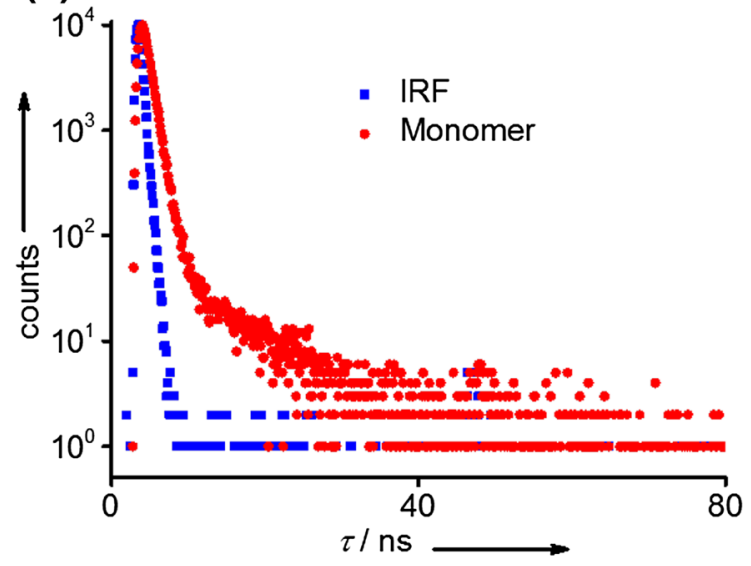

(b)

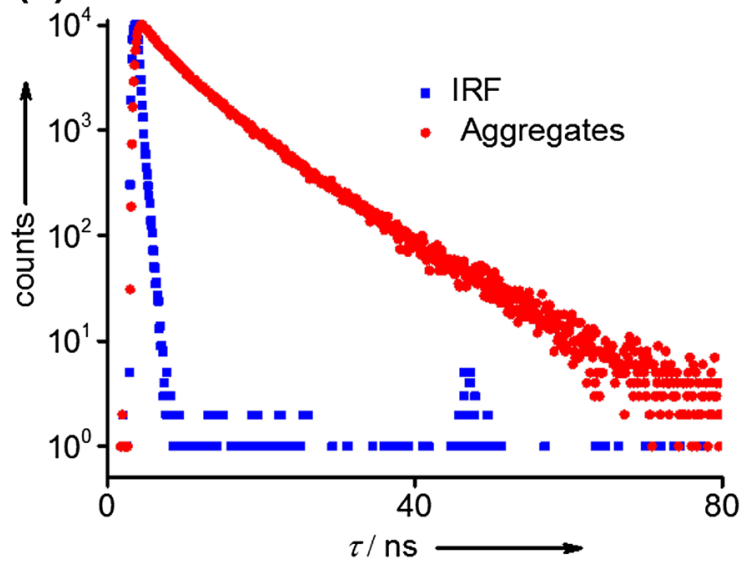

Figure 2. Fluorescence decay profiles of 1: (a) in DMSO (monomeric species) and (b) in water:DMSO (95:5) (aggregated species) at $20^{\circ} \mathrm{C}$.

$90{ }^{\circ} \mathrm{C}$ (Figure 1d). The emission maximum of $\mathbf{1}$ in water:DMSO at $90^{\circ} \mathrm{C}$ is matching with the emission maximum of $\mathbf{1}$ in DMSO. However, no significant change is observed in the absorption spectrum with the increase in temperature. These results indicate that monomeric species of $\mathbf{1}$ is weakly emissive and the fluorescence is significantly enhanced upon aggregation. It is also to be mentioned that emission maximum of the aggregated species obtained at $10 \%$ water is matching with the emission maximum at $95 \%$, suggesting that aggregated species formed at two different water percentages are having the same optical behavior (Figure 1c). Furthermore, emission studies of $\mathbf{1}$ was carried out in the solid state. The emission spectrum shows a broad peak in the range of 350 to $600 \mathrm{~nm}$ with an emission maximum centered at $440 \mathrm{~nm}\left(\lambda_{\text {exc }} 320 \mathrm{~nm}\right)$. Though the spectral nature is nearly identical to the emission spectrum of the aggregated species in solution, a blue-shift of $20 \mathrm{~nm}$ is observed when comparing the emission maximum of the aggregated species in solution (Figure 1f). These observations suggest that different packing modes for the aggregates of $\mathbf{1}$ in the solid and solution states. To gain more insight into the mechanism of fluorescence enhancement for the aggregated species, detailed time-resolved fluorescence experiments were carried out on the monomeric (DMSO) and aggregated (water:DMSO) species of 1 (Figure 2). The excitation wavelength for the lifetime experiments was $310 \mathrm{~nm}$. For the monomeric species, the emission was collected at $356 \mathrm{~nm}$ and for the aggregated species, the emission was collected at $460 \mathrm{~nm}$. A very fast decay with fluorescence lifetime comparable to the pumping laser pulse width ( $<1 \mathrm{~ns}$, Horiba Scientific NanoLED-310) is observed for the monomeric species. Hence, a lifetime of $\sim 1 \mathrm{~ns}$ is assumed for $\mathbf{1}$ monomeric species. This very fast decay can be attributed to the fast non-radiative relaxation of the excited state, and in this case, most possibly through intramolecular $\mathrm{C}\left(\mathrm{sp}^{2}\right)-\mathrm{C}\left(\mathrm{sp}^{2}\right)$ bond rotation owing to their low rotational energy barrier as observed in similar systems. ${ }^{10}$ On the other hand, significantly longer lifetime is observed for the aggregated state of 1 with an average lifetime of 8.37 ns. Furthermore, a higher non-radiative decay rate constant $\left(k_{\mathrm{nr}}=9.17 \times 10^{8} \mathrm{~s}^{-1}\right)$ than the radiative decay rate constant $\left(k_{\mathrm{r}}=0.69 \times 10^{8} \mathrm{~s}^{-1}\right)$ is observed for the monomeric species of 1 . On the other hand, in the aggregated state, the nonradiative rate constant $\left(k_{\mathrm{nr}}=0.84 \times 10^{8} \mathrm{~s}^{-1}\right)$ is significantly reduced, whereas the radiative rate constant $\left(k_{\mathrm{r}}=0.36 \times 10^{8} \mathrm{~s}^{-1}\right)$ is nearly the same when compared to corresponding monomeric state (Table 1). This significant lowering of non-radiative rate constant in the case of aggregated state indicates substantial reduction of the non-radiative relaxation (intramolecu$\operatorname{lar} \mathrm{C}\left(\mathrm{sp}^{2}\right)-\mathrm{C}\left(\mathrm{sp}^{2}\right)$ bond rotation) of the excited state of the aggregated species. This results in the intramolecular planarization of the tetraphenylethylene as evident from the redshift in emission, and makes radiative recombination as the dominant decay channel for the excited state and thereby enhances the emission. These observations are typical for the molecule having the phenomenon of AIEE. Moreover, in order to rule out that the observed fluorescence changes for the aggregated species are not due to the mere effect of temperature, temperaturedependent fluorescence studies were carried out on the monomeric species of $\mathbf{1}$. Dendron $\mathbf{1}$ exists as monomeric species in DMSO. Temperature-dependent fluorescence studies of monomeric species of $\mathbf{1}$ show quenching of fluorescence without any shift in the emission maximum, showing the mere effect of temperature on the fluorescence of $\mathbf{1}$ (Figure 1e). On the other hand, temperature dependent fluorescence studies of the aggregates of $\mathbf{1}$ show quenching of fluorescence with a 
Table 1. Spectroscopic data of $\mathbf{1}$ in monomeric and aggregated states.

\begin{tabular}{lcccc}
\hline State & $\Phi_{\mathrm{f}}$ & $<\tau_{\mathrm{av}}>[\mathrm{ns}]$ & $k_{\mathrm{nr}} / 10^{8}\left[\mathrm{~s}^{-1}\right]$ & $k_{\mathrm{r}} / 10^{8}\left[\mathrm{~s}^{-1}\right]$ \\
\hline Monomer of $\mathbf{1}$ & 0.07 & $\sim 1.00$ & 9.17 & 0.69 \\
Aggregates of $\mathbf{1}$ & 0.30 & 8.37 & 0.84 & 0.36 \\
\hline
\end{tabular}
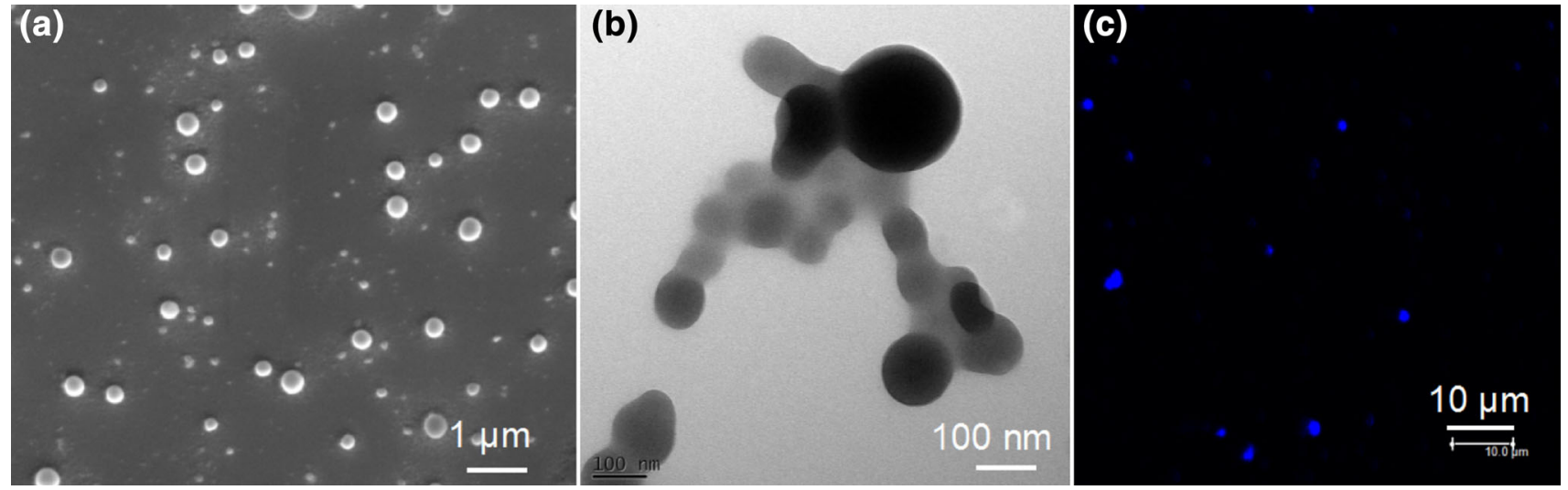

Figure 3. (a) SEM, (b) TEM and (c) confocal microscopic images of 1 in 95:5 of water:DMSO ([1] $=20 \mu \mathrm{M})$.

concomitant blue-shift, which is a characteristic spectral change for the disassembly of tetraphenylethylenebased aggregates. These results unequivocally confirm that the monomeric species of $\mathbf{1}$ is weakly emissive due to the intramolecular $\mathrm{C}\left(\mathrm{sp}^{2}\right)-\mathrm{C}\left(\mathrm{sp}^{2}\right)$ bond rotation and the enhancement in the emission in the aggregated state is due the phenomenon of AIEE.

\subsection{Microscopic studies}

In order to understand the morphology of the aggregated species, very detailed microscopic analyses were carried out. Scanning electron macroscopic analyses show the formation of spherical particles (Figure 3a). The approximate size of the particle ranges from 100 to $300 \mathrm{~nm}$. To gain further insight into the nature of the nanoparticles, TEM analyses were performed. TEM analysis also shows the formation of spherical particles with the size ranging from 100 to $200 \mathrm{~nm}$ (Figure 3b). Importantly, the contrast difference between the periphery and the inner part of the spherical aggregate in the TEM images is typically used to distinguish between the vesicular or micellar nature of the spherical particles. A clear contrast difference is a characteristic feature of vesicles whereas the absence of contrast difference suggests the formation of micellar or solid nanoparticles. It is very clear from the TEM images that no contrast difference exists between the periphery and inner part of the spherical aggregates, which clearly rules out the vesicular nature of the aggregate. Since the diameter of the particle is significantly larger than twice the molecular length $(\sim 4.2 \mathrm{~nm})$ of $\mathbf{1}$ the particles are not micellar in nature as well. These observations confirm that the spherical aggregates are solid nanoparticles. Since the nanoparticles are emissive in nature, we have used confocal microscope also to characterize the formation of nanoparticles. Confocal microscopic analyses reveal the formation of blue emissive nanoparticle (Figure 3c). This is in accordance with the fluorescence behavior of the molecule.

\section{Conclusions}

In summary, we have reported the synthesis of a new derivative of tetraphenylethylene using multi-step organic reactions. Steady and time-resolved fluorescence studies have shown that the monomeric state of the molecule is weakly emissive due to the rotational relaxation of the excited state. A strong AIEE was observed for the aggregated species, which is attributed to the restriction of intramolecular $\mathrm{C}\left(\mathrm{sp}^{2}\right)-\mathrm{C}\left(\mathrm{sp}^{2}\right)$ bond rotation. Microscopic analyses have shown the formation of spherical nanoparticle for the aggregated species. Confocal microscopic analyses have revealed the formation of blue emissive nanoparticles. We hope the unique behavior of enhanced emission of the molecules in the aggregated state may attract researchers to explore this kind of molecules for application in material science, particularity in light emitting diodes. Our results are 
also expected to open up further research interest in the design of new tetraphenylethylene derivatives for bioimaging applications.

\section{Acknowledgements}

Financial support from KSCSTE (KSYSA Grant) is gratefully acknowledged. We thank UGC (N. K.) and CSIR (D. P.) for research fellowships.

\section{References}

1. (a) Magginia L and Bonifaz D 2012 Hierarchized Luminescent Organic Architectures: Design, Synthesis, Selfassembly, Self-organization and Functions Chem. Soc. Rev. 41 211; (b) Messmore B W, Hulvat J F, Sone E D and Stupp S I 2004 Synthesis, Self-Assembly, and Characterization of Supramolecular Polymers from Electroactive Dendron Rodcoil Molecules J. Am. Chem. Soc. 126 14452; (c) Han J, You J, Li X, Duan P and Liu M 2017 Full-Color Tunable Circularly Polarized Luminescent Nano-assemblies of Achiral AIEgens in Confined Chiral Nanotubes Adv. Mater. 291606503

2. (a) Figueira T M, Rosso P G D, Trattnig R, Sax S, List E J W and Müllen K 2010 Designed Suppression of Aggregation in Polypyrene: Toward High-performance Blue-light-emitting Diodes Adv. Mater. 22 990; (b) Shiraishi K, Kashiwabara T, Sanji T and Tanaka M 2009 Aggregation Induced Emission of Dendritic Phosphole oxides New J. Chem. 33 1680; (c) Miyake J and Chujo Y 2008 Thermally Stabilized Blue Luminescent Poly(p-phenylene)s Covered with Polyhedral Oligomeric Silsesquioxanes Macromol. Rapid Commun. 29 86; (d) Satrijo A, Kooi S E and Swager T M 2007 Enhanced Luminescence from Emissive Defects in Aggregated Conjugated Polymers Macromolecules 40 8833; (e) Wang J, Zhao Y, Dou Y C, Sun H, Xu P, Ye K, Zhang J, Jiang S, Li F and Wang Y 2007 Alkyl and Dendron Substituted Quinacridones: Synthesis, Structures, and Luminescent Properties J. Phys. Chem. B 111 5082

3. Masai H, Terao J, Seki S, Nakashima S, Kiguchi M, Okoshi K, Fujihara T and Tsuji Y 2014 Synthesis of One-Dimensional Metal-Containing Insulated Molecular Wire with Versatile Properties Directed toward
Molecular Electronics Materials J. Am. Chem. Soc. 136 1742; (b) Terao J, Homma K, Konoshima Y, Imoto R, Masai H, Matsuda W, Seki S, Fujiharaa T and Tsujia Y 2014 Synthesis of Functionalized Insulated Molecular Wires by Polymerization of an Insulated p-Conjugated Monomer Chem. Commun. 50658

4. Liang J, Tang B Z and Liu B 2015 Specific Light-up Bioprobes Based on AIEgen Conjugates Chem. Soc. Rev. 44 2798; (b) Hong Y, Lama J W Y and Tang B Z 2009 Aggregation-induced Emission: Phenomenon, Mechanism and Applications Chem. Commun. 4332

5. Hong Y, Lama J W Y and Tang B Z 2011 Aggregationinduced Emission Chem. Soc. Rev. 405361

6. Lee Y T, Chang Y T, Chen C T and Chen C T 2016 The First Aggregation-induced Emission Fluorophore as a Solution Processed Host Material in Hybrid White Organic Light-emitting Diodes J. Mater. Chem. C 4 7020; (b) Hong Y 2016 Aggregation-induced EmissionFluorophores and Applications Methods Appl. Fluoresc. 4022003

7. Ding D, Li K, Liu B and Tang B Z 2013 Bioprobes Based on AIE Fluorogens Acc. Chem. Res. 46 2441; (b) Zhao Y, Yu C Y Y, Kwok R T K, Chen Y, Chen S, Lamab J W Y and Tang B Z 2015 Photostable AIE Fluorogens for Accurate and Sensitive Detection of S-phase DNA Synthesis and Cell Proliferation J. Mater. Chem. B 3 4993

8. Liu Y, Deng C, Tang L, Qin A, Hu R, Sun J Z and Tang B Z 2011 Specific Detection of D-Glucose by a Tetraphenylethene-Based Fluorescent Sensor $J$. Am. Chem. Soc. 133 660; (b) Shi H, Liu J, Geng J, Tang B Z and Liu B 2012 Specific Detection of Integrin Rv $\beta 3$ by Light-up Bioprobe with AggregationInduced Emission Characteristics J. Am. Chem. Soc. 134 9569

9. La D D, Bho sale S V, Jones L A and Bhosale S V 2018 Tetraphenylethylene-Based AIE-Active Probes for Sensing Applications ACS Appl. Mater. Interfaces 10 12189; (b) Cai Y, Shi C, Zhang H, Chen B, Samedov K, Chen M, Wang Z, Zhao Z, Gu X, Ma D, Qin A and Tang B Z 2018 Sulfur-bridged Tetraphenylethylene AIEgens for Deepblue Organic Light-emitting Diodes J. Mater. Chem. C 66534

10. Albert S K, Thelu H V P, Golla M, Krishnan N, Chaudhary S and Varghese R 2014 Self-Assembly of DNAOligo(p-phenyleneethynylene) Hybrid Amphiphiles into Surface-Engineered Vesicles with Enhanced Emission Angew. Chem. Int. Ed. $\mathbf{5 3} 8352$ 